\title{
Biotecnología y derechos humanos: ¿complementariedad o conflicto?
}

BENITO DE CASTRO CID

Catedrático de Filosofla del Derecho, UNED

Entre otros motivos de esperanza o de preocupación, el pasado siglo nos ha traído la posibilidad real de adentrarnos, a través de los misteriosos túneles del ADN, hasta la cámara en que se mantenía oculto el oscuro germen de la vida. De ahí que el gran potencial que encierra la biotecnología para la transformación de los dinamismos que, con férreo automatismo, han venido dirigiendo durante millones de años el desarrollo de los seres vivos haya disparado de inmediato la alarma de nuestras tradicionales convicciones éticas. En efecto, según los primeros indicios, nos encontramos situados ante la inquietante frontera de un nuevo territorio científico y moral que no sabemos cómo ni por dónde ha de ser caminado. Y, aunque intuimos que puede sernos útil el mapa de carreteras de los derechos humanos ${ }^{1}$, no sabemos todavía con certeza hasta qué punto... Por eso, tenemos que sopesar atenta y cuidadosamente la ayuda que ese mapa puede prestarnos ${ }^{2}$. 
Hemos de comenzar reconociendo que el futuro desarrollo de los principales campos en que se ha centrado tradicionalmente la actuación de los hombres sobre el medio en que viven está colgado del clavo de las aplicaciones biotecnológicas. Tanto la industria como la agricultura, la ganadería o la medicina, no sólo son ya generosos campos de experimentación de la biotecnología, sino que, gracias a esa experimentación, están registrando avances ciertamente espectaculares.

En el ámbito de la industria, gracias a los avances de la microbiología y de la ingeniería genética molecular, la consecución de productos cada vez más evolucionados y eficaces en el campo de la alimentación, los medicamentos, los fertilizantes, los combustibles, las fibras, los plásticos o las pinturas se ha convertido ya en normal desde hace bastante tiempo. A su vez, en la agricultura, la utilización de plantas de crecimiento rápido, que tengan una producción mucho mayor, que den frutos con un contenido alimenticio predeterminado artificialmente o que maduren en un tiempo mucho más corto es ya un hecho. Y lo es también el logro de plantas capaces de desarrollarse en suelos hasta ahora improductivos, plantas resistentes a enfermedades y parásitos e, incluso, plantas que producen sus propios fertilizantes. Del mismo modo, en el campo de la ganadería, las aplicaciones biotecnológicas han dejado ya completamente obsoleta la vieja práctica de mejora de las razas animales mediante la selección y los cruces interespecíficos. Hoy, mediante la manipulación de las moléculas de la vida, resulta ya posible, no sólo la procreación de animales transgénicos que estén especialmente adaptados a determinadas necesidades humanas o que produzcan hormonas, tejidos y órganos que puedan ser útiles para los humanos, sino también la propia duplicación genética del individuo ${ }^{3}$. Y en el ámbito de la medicina, el recurso a los avances biotecnológicos ha permitido conquistar objetivos casi inimaginables, tanto en la línea diagnóstica, como en la terapéutica o la reproductiva ${ }^{4}$. En efecto, el diagnóstico y terapia génicos, 
tras la localización de los genes 'responsables' de ciertas enfermedades hereditarias, permiten eliminar la raiz de tales enfermedades mediante la sustitución o modificación funcional de los genes defectuosos. Y han abierto también la puerta a la posibilidad real de incorporar al equipamiento psicobiológico del individuo determinados genes que son portadores de rasgos o caracteres considerados deseables (como sexo, grado y tipo de inteligencia, cualidades psicosomáticas, color del pelo, los ojos o la piel, etc. $)^{5}$.

Es, pues, evidente que la biotecnología tiene hoy la capacidad de alterar muy profundamente el curso de los dinamismos naturales que han guiado durante millones de milenios el nacimiento y desarrollo de los seres vivos. $Y$ esta inusitada capacidad ha hecho que muchos hombres contemplen el horizonte de los avances biotecnológicos bajo la presion de dos sentimientos difícilmente conciliables: de un lado, la esperanza en un considerable despegue de la calidad de su vida y, de otro, el temor a unos riesgos que se entrevén amenazadores y tremendamente graves para el futuro de la humanidad Hoy se tiene la creencia de que debemos fiarnos de los conocimientos de los científicos, pero muchos piensan que no en demasía, pues podría ocurrir que la inevitable limitación de esos conocimientos les colocara de nuevo en una situación similar a aquéllas otras del pasado en que no fueron capaces de prever el desarrollo de bacterias resistentes a los antibióticos o los dañinos efectos de ciertos medicamentos estrella [como la tristemente famosa talidomida] y de algunos de los insecticidas más universalmente empleados [como el DDT $]^{6}$.

Se tiene, por tanto, en la actualidad la inquietante conciencia de que, si bien la biotecnología está abriendo paso hacia unas posibilidades inéditas en la lucha por el bienestar de la humanidad en todos los ámbitos de la vida, su aplicación incontrolada podría ser también un nuevo caballo de Troya que despejara el camino a ciertos daños muy graves para algunos de los bienes o intereses básicos de esa humanidad. Y ahí, en esa conciencia escindida, es donde surge el preocupante enigma ético de 
los deslumbrantes avances biotecnológicos y la consiguiente necesidad de contar con unos principios o valores que puedan ser generalmente asumidos como patrón de contraste de su corrección o incorrección. ¿Dónde encontrarlos?

Podrán ser ofrecidas sin duda otras muchas direcciones de interés, pero yo tengo la convicción íntima de que, a fecha de hoy, esos principios han de ser buscados en el territorio amigo de los derechos humanos. No en vano estos derechos son generalmente reconocidos y aceptados en la actualidad como compendio y horizonte de un código ético, jurídico y político universalmente aplicable.

\section{EL PAPEL ORIENTADOR DE LOS DERECHOS HUMANOS}

¿Qué pueden decirnos los derechos humanos sobre la corrección o incorrección ética y jurídica de las distintas intromisiones biotecnológicas en el curso de la fecundación, gestación y desarrollo de los propios hombres o de los seres que constituyen su entorno existencial más próximo?

Es esta una pregunta difícil, ya que el sentido y alcance de la incidencia que las aplicaciones biotecnológicas pueden tener en el efectivo disfrute de los derechos humanos no están nunca definidos a priori. Como simple haz de potenciales actuaciones técnicas, la biotecnología tiene la capacidad de colaborar en un disfrute mucho más pleno de los derechos, tanto como de convertirse en una seria amenaza para ese disfrute. Así que todo dependerá de los efectos que produzca en cada caso su aplicación.

Por otra parte, tampoco está despejada la incógnita de los derechos humanos cuyo efectivo ejercicio se ve directamente afectado por las diversas actuaciones biotecnológicas posibles ${ }^{7}$. Es cierto que existe entre los estudiosos del tema una especie de consenso fáctico que hace recalar sus análisis sobre la vida, la dignidad, la libertad, la igualdad, la intimidad, el me- 
dio ambiente 0 , más recientemente, el patrimonio genético. Pero no es fácil entender por qué no se detienen también en la consideración de otros varios derechos que, como la salud, el nivel satisfactorio de vida, la integridad psicofísica o la libre investigación, parecen encontrarse en la línea natural de avance de esas actuaciones.

Sin embargo, también resulta evidente que el tiempo asignado a una sola sesión de las Jornadas no permite realizar el contraste de todos los derechos presuntamente involucrados, imponiéndose, por tanto, la selección de aquellos que pueden tener en el momento actual una significación más acusada: derecho a un nivel satisfactorio de vida, derecho al medio ambiente, derecho a la integridad psicofísica, derecho al libre desarrollo de la personalidad y derecho al patrimonio genético.

\section{A) DERECHO A UN NIVEL SATISFACTORIO DE VIDA}

La Declaración Universal de Derechos Humanos ha proclamado, en su artículo 25, que "toda persona tiene derecho a un nivel de vida adecuado". A su vez, el artículo 11.1 del Pacto Internacional de Derechos Económicos, Sociales y Culturales ha completado este derecho con el de "una mejora continua de las condiciones de existencia"8. Cabe hablar, por tanto, del 'derecho a un nivel satisfactorio de vida' como derecho naturalmente complementario del simple y radical 'derecho a la vida' (al menos, si éste no es entendido ya como un derecho general que incluye todos los aspectos y dimensiones en que se proyecta el disfrute íntegro y pleno de la vida como hecho primario de la propia existencia) ${ }^{9}$. Y, dado que las actuaciones biotecnológicas siempre terminan incidiendo de alguna forma en el horizonte de las expectativas vitales de los hombres, resulta obvio entender que tienen mucho que ver con las posibilidades de disfrute de un nivel satisfactorio de vida, de modo que podrían establecerse en este punto dos conclusiones básicas. Por un lado, la que afirma que tales actuaciones deben ser amparadas y promovidas siempre en todos aquellos ámbitos que contribuyan, directa o indirectamente, a incrementar la calidad de vida de la humanidad. Y, por otro, la que re- 
chaza el recurso a esas actuaciones siempre que exista un riesgo grave de que se produzca algún perjuicio irreversible, directo o indirecto, en las condiciones de vida de cada hombre particular o de todos los hombres en general.

\section{B) DERECHO AL MEDIO AMBIENTE}

Hemos de reconocer que el desarrollo industrial ha ido acompañado casi siempre de una galopante invasión del santuario de la naturaleza y de un paralelo deterioro del medio en que sobreviven las plantas, los animales y los hombres. Pero han sido los avances de la biotecnología los que han puesto al alcance de la actividad industrial la mutación interna y profunda de ese medio, a través de las manipulaciones genéticas de plantas, animales y hombres.

Se teme, pues, no sin cierta razón, que las actuaciones biotecnológicas incontroladas sobre las plantas y los animales para modificarle algunos de sus caracteres génicos recorten progresivamente la biodiversidad y lleguen a tener efectos negativos irreversibles sobre el habitat humano. Mas, por otra parte, se entrevé también que la biotecnología cuenta con capacidad suficiente para poner remedio al actual desgaste de la biosfera de forma no traumática, es decir, sin cortar bruscamente con el tipo de progreso y bienestar que ha alcanzado la humanidad ${ }^{10}$. Y, en esa medida, se tiene la convicción de que el derecho al medio ambiente puede encontrar en la biotecnología un poderoso y eficaz aliado. Pero se tiene también el temor de que un aliado tan poderoso termine convirtiéndose finalmente en un temible enemigo. Y, por eso, se acepta la necesidad de vigilar todos sus movimientos de forma permanente con el rabillo del inquieto ojo ético para que su enorme poder técnico no ponga nunca en peligro el equilibrio y la viabilidad del habitat humano.

\section{C) DERECHO A LA INTEGRIDAD PSICOFÍSICA}

No cabe duda de que el aspecto de la biotecnología que ofrece más dificultades a cualquier proyecto de homologación ética es el que inter- 
viene de forma directa en el equipamiento vital de cada hombre. Por otra parte, resulta también evidente que cualquier tipo de actuación biotecnológica sobre ese equipamiento termina afectando en alguna medida a la integridad psicofísica del individuo. Pero no fácil determinar cuándo una determinada actuación está contribuyendo a la mejor realización del correspondiente derecho o está, por el contrario, poniendo en peligro su pacífico disfrute.

En efecto, la posibilidad de que los diagnósticos y las terapias génicas abran el camino de la sustitución o modificación de los genes defectuosos ${ }^{11}$ (así como de la incorporación de otros que sean portadores de rasgos considerados beneficiosos) parece, en principio, una magnífica contribución al efectivo disfrute del derecho a tener un equipamiento biopsicológico plenamente sano. Sin embargo, ha de reconocerse que pueden dar paso también, no sólo a prácticas eugenésicas de carácter discriminatorio, sino incluso a intervenciones selectivas que mutilen gravemente la integridad psicofísica de ciertos individuos asilados o de los individuos de determinados grupos sociales considerados margina$\operatorname{les}^{12}$. Y, en esa medida, la pregunta verdaderamente importante es la de si las intervenciones biotecnológicas son o no incompatibles con el derecho a la integridad psicofísica. Veamos.

Creo, en primer lugar, que las actuaciones biotecnológicas en la línea somática no presentan diferencias cualitativas relevantes en relación con las intervenciones quirúrgicas tradicionales, por lo que no deberían considerarse tampoco lesivas del derecho a la integridad psicofísica. Del mismo modo creo que, en el caso de las aplicaciones realizadas en la línea germinal, resultaría poco razonable llevar la eficacia protectora del derecho a la integridad psicofísica más allá de las intromisiones que produzcan algún tipo de deterioro o pérdida irreversible en el equipamiento vital del sujeto. Así que, cuando las aplicaciones biotecnológicas respondan al objetivo de corregir alguna deficiencia grave del propio individuo directamente afectado, habrá que entender que tales aplicaciones no se oponen al núcleo básico de exigencias del derecho a la in- 
tegridad. ¿Habrá que entenderlo igualmente cuando esas aplicaciones van destinadas a corregir las deficiencias de otros sujetos distintos del directamente afectado o a mejorar la dotación psicofísica de ciertos individuos o grupos?

En estos supuestos las cosas están mucho menos claras. Considero dudoso, en primer lugar, que la manipulación genética orientada al logro de un organismo humano que pueda proporcionar elementos capaces de corregir las patologías de otros individuos ${ }^{13}$ no entre en conflicto con el viejo principio fundante de los derechos humanos de que los hombres han de ser tomados siempre como fines en sí mismos y nunca como medios para la realización de fines ajenos. Y no estoy totalmente seguro de que todas las aplicaciones biotecnológicas dirigidas a mejorar la dotación psicofísica individual queden amparadas siempre por el criterio del mayor beneficio para el sujeto. Puede haber ocasiones en que esas aplicaciones obedezcan a una simple utilización intrumental de los seres humanos con vistas al logro de determinados objetivos científicos o sociales difícilment justificables. En esos supuestos, serán éticamente inadmisibles.

D) DERECHO AL LIBRE DESARROLLO DE LA PERSONALIDAD

Se reconoce generalmente que el núcleo esencial del derecho al libre desarrollo de la personalidad está formado por la libertad de elección y configuración de la trayectoria que va a seguir la propia vida. Y se reconoce asimismo que la realización del derecho queda directamente vinculada al respeto que se tenga hacia esa libertad de elección. En esa medida, puede afirmarse también que la relación entre las actuaciones biotecnológicas y el derecho al libre desarrollo de la personalidad sólo llegará a ser conflictiva si tales actuaciones son realizadas violentando de alguna forma la autonomía del sujeto afectado, ya sea porque son realizadas en contra de su voluntad expresa, ya sea porque se llevan a cabo al margen de la misma. Consecuentemente, para salvaguardar la autonomía individual, se exige que las actuaciones biotecnológicas queden siempre subordinadas al previo consentimiento libre e informado del sujeto afec- 
tado (o de quienes estén legitimados para decidir en su lugar), de tal modo que, en caso contrario, serían siempre injustificables ${ }^{14}$. Pero esta conclusión no parece contar con un aval suficientemente sólido, habida cuenta de que los individuos nacen y se realizan como personas dentro del contexto existencial de una muy determinada organización social ${ }^{15}$.

Deberá aceptarse, en consecuencia, la conclusión de que la imposición vinculante de ciertos análisis o terapias genéticas en determinados casos podría resultar avalada por razones de tanto o mayor peso que el del derecho de libre determinación de la personalidad. Así podría ocurrir, por ejemplo, en los supuestos de consejos prematrimoniales y prenatales, de prevención sanitaria general o individual frente a ciertos tipos de enfermedad y de pruebas para el desempeño de trabajos o funciones sociales que entrañen graves riesgos para terceros. $\mathrm{Y}$ podría ocurrir también en el ámbito de la administración de justicia, cuando se está ante litigios relacionados con la paternidad, la vida, la integridad física o la libertad sexual.

E) DERECHO AL PATRIMONIO GENÉTICO

En la actualidad, el debate sobre la corrección o incorrección ética de las actuaciones biotecnológicas incluye casi siempre la referencia al 'derecho al patrimonio genético', según todos los indicios con la pretensión de levantar una especie de dique frente al posible avance incontroladamente invasivo de tales actuaciones. Sin embargo, en este punto, parece necesario comenzar con una importante duda: ¿puede hablarse con fundamento de un derecho al patrimonio genético o deberá pensarse más bien que la conservación de este patrimonio está amparada ya por el derecho a la integridad psicofísica?

Yo pienso que esta segunda opción es la más plausible, pero no estoy muy seguro de que vaya a ser la más aceptada. Y, en consecuencia, entreveo la posibilidad de que este nuevo derecho, no sólo tendrá una generosa acogida doctrinal, sino que llegará incluso a ser formalmente incorporado muy pronto al elenco 'oficial' de los derechos humanos. Es, 
pues, probable que el derecho al patrimonio genético forme parte, en un futuro muy próximo, de la frontera ética que delimita el territorio de las aplicaciones biotecnológicas. Tenemos que tomarlo, por tanto, en consideración ${ }^{16}$.

Es, sin embargo, obligado dejar constancia de que la afirmación de este nuevo derecho ofrece todavía múltiples flancos de incertidumbre, por lo que ha de ser considerada, cuando menos, prematura. Por ejemplo, no hay constancia de que, a la hora de establecer el valor objetivo y los límites del llamado patrimonio genético de la humanidad (y de todos los demás seres de la naturaleza), se haya ponderado adecuadamente el impacto que las mutaciones genéticas espontáneas han tenido en él a lo largo de la historia. Y no se tiene claro tampoco si (al margen de las creencias ético-religiosas) la medida de su valor directivo y regulador ha de ser la mayor o menor 'naturalidad' o 'artificialidad' del proceso o, por el contrario, la propia calidad vital de los resultados conseguidos.

Por otra parte, la consideración del patrimonio genético humano como un valor supremo y como un bien unitario del que sería titular único la humanidad en su conjunto (incluidas las generaciones futuras), implica un grado de exaltación sacralizadora muy difícil de admitir, tal como ha señalado C. M. Romeo CASABONA en referencia al genoma ${ }^{17}$.

Así que el recurso a este posible derecho nos coloca ya en la frontera del futuro. Y, tal vez, cuando llegue a ser rigurosamente formulado, no amparará, como ahora, la defensa del actual patrimonio frente a las manipulaciones biotecnológicas, sino más bien algo directamente opuesto a la conservación de ese patrimonio: el deseo de beneficiarse de las hoy imprevistas ventajas de esas manipulaciones para transformarlo profundamente.

\section{F) DERECHO A LA LIBERTAD DE INVESTIGACIÓN}

La libertad de investigación, como la libertad de pensamiento o la libertad de creencia, ha tenido que convivir siempre con la sospecha de constituir una peligrosa trampa para la seguridad y tranquilidad de los individuos o para la integridad de los respectivos sistemas sociales. $\mathrm{Pe}-$ 
ro ese triste destino cultural se ha visto desmentido siempre por una larga y acrisolada experiencia y hoy tenemos ya clara constancia de que, a lo largo de todas las épocas históricas, ha sido precisamente esa libertad el verdadero motor del progreso y del bienestar de la humanidad en todos los ámbitos de la vida. De modo que, a pesar del inmenso potencial destructor que posee actualmente, la biotecnología no puede ser excluida del campo de aplicación de un principio que, como el de libre investigación, forma parte del patrimonio espiritual de los hombres y ha sido siempre el principal motor de desarrollo de todos los saberes ${ }^{18}$.

Debe reconocerse, no obstante, que el ejercicio del derecho a la libertad de investigación en el campo de la biotecnología podría entrar en conflicto con otros derechos preferentes, si ese ejercicio implicara un riesgo directo o indirecto, pero cierto, para el justo disfrute de los mismos por parte de sus titulares ${ }^{19}$. Y, en esa medida, como en el caso de todos los demás derechos humanos, el ejercicio de la libertad de investigación está sujeto a limitaciones ${ }^{20}$. Consecuentemente, la libertad de aplicación técnica de los conocimientos biotecnológicos podría quedar también sujeta a limitaciones, no sólo para el biotecnólogo, como parece obvio, sino también para los demás miembros de la sociedad ${ }^{21}$. Pero, fuera de esos supuestos, la libre investigación deber ser respetada y promovida como bien originario de la autonomía individual y como valor básico de la organización social abierta y progresiva ${ }^{22}$.

\section{3. ¿UN POSIBLE CÓDIGO ETICO-JURÍDICO DE}

\section{LAS APLICACIONES BIOTECNOLÓGICAS?}

El breve repaso testimonial de la influencia que las aplicaciones biotecnológicas pueden tener sobre las expectativas de realización de los derechos examinados permite establecer algunas conclusiones que, a pesar de su inevitable carácter provisional, podrían ser asumidas, en mi opinión, como núcleo inicial de un futuro código fundamental de direc- 
trices o principios ético-jurídicos de orientación. Entre esas conclusiones podrían figurar las siguientes:

$1^{a}$. No es razonable entender que los derechos humanos están 'naturalmente' llamados a actuar como dique o frontera infranqueable frente a los avances científico-técnicos relacionados con las posibilidades de intervención en los procesos bioquímicos de reproducción de los seres vivos. Debe entenderse, por el contrario, que la propia funcionalidad protectora y promotora de los derechos humanos incluye el compromiso de impulsar la aplicación de tales avances en la medida en que éstos puedan contribuir a mejorar la calidad de vida de los hombres. Así que la pregunta sobre si la relación que une a la biotecnología con los derechos humanos se estructura en torno al conflicto o, por el contrario, en torno al principio de la complementariedad ha de ser contestada en el sentido predominante de esta última.

$2^{a}$. Los derechos humanos no pueden ser utilizados como una fuente general de orientación ética y jurídica de la experimentación genética y de las actuaciones biotecnológicas cuando los seres manipulados no reúnen las condiciones vitales que obligarían a reconocer que son verdaderos sujetos humanos o cuando tales experimentos o actuaciones no afectan de una forma relevante a ninguno de los sujetos de los que pueden predicarse esos derechos.

Sin embargo, por cuanto parece evidente que el material genético humano participa siempre en algún grado de la dignidad propia de los hombres, las prácticas que supongan un trato denigrante o meramente instrumental de ese material deberán ser radicalmente rechazadas, salvo que resulte razonable prever que proporcionarán importantes efectos beneficiosos para los individuos o para la colectividad. Y, por razones de afinidad biológica, deberán ser rechazadas también en los mismos supuestos todas las prácticas con material genético animal o vegetal.

$3^{a}$. No parece tampoco razonable invocar los derechos humanos de integridad psicofísica para bloquear la aplicación de la terapia génica en 
la línea somática, con independencia de que los pacientes estén en fase embrionaria, sean fetos o hayan nacido. Y, por lo que se refiere a la aplicación de esa terapia en la línea germinal, no deberían oponerse más objeciones que a cualquier otra técnica de prevención de enfermedades. De modo que, en principio, cualquier duda deberá resolverse mediante la aplicación de la regla prudencial de que el cálculo de las ventajas para el individuo o para la especie supere, en cantidad y calidad, al de los riesgos.

$4^{\mathrm{a}}$. No se ve razón fuerte que impida legitimar las intervenciones eufenésicas en el genoma humano, aunque no tengan un carácter estrictamente curativo. Pero debe darse siempre una condición grave: que los potenciales riesgos para el propio individuo, para sus descendientes o para alguno de los valores básicos de la humanidad tengan menos relevancia que las ventajas y beneficios previsibles.

5 . La libertad de investigación es un valor cultural de primer orden y un derecho humano básico, pero esta libertad, al igual que todos los demás derechos de libertad, está limitada por los bienes o valores que, siendo tan importantes o más que ella misma, son sometidos a un riesgo probable por el desarrollo de la investigación. El límite de la libertad investigadora está, por tanto, no sólo en la existencia de daños ciertos, sino también en la presencia de un riesgo probable de que esos daños lleguen a producirse.

$6^{a}$. En el supuesto de conflicto entre una determinada actuación biotecnológica y el pacífico disfrute de un determinado derecho humano, el correspondiente proceso de valoración deberá abrirse a la ponderación de todos los diferentes derechos e intereses básicos que puedan estar en juego ${ }^{23}$.

Son seis reglas que podrían resumirse incluso en un único criterio básico de orientación. Este: las actuaciones biotecnológicas son, en principio, un buen camino para que todos los seres humanos puedan acceder con mayor plenitud al disfrute de sus derechos primarios, pero 
tendrán un déficit radical de legitimación siempre que impliquen un peligro cierto de producir daños irreversibles y graves en la vida, la salud y la integridad psicofísica de los hombres o del conjunto de plantas y animales sin los que parece que resultaría inviable la vida humana. $\mathrm{El}$ interés o bien objetivo de los hombres, como individuos y como humanidad, es, pues, el principio supremo y definitivo para la valoración ético-jurídica de cualquier actuación biotecnológica. 
1 El imprevisible horizonte abierto en el campo de la ética por los avances biotecnológicos obliga a disponer de un código de principios que puedan ser asumidos como guía para contrastar el nivel de corrección de las diversas actuaciones biotecnológicas. $Y$ ese código puede encontrarse sin duda en el campo de los derechos humanos, ya que éstos son generalmente aceptados en la actualidad como supremo referente ético de toda la humanidad. Pero resulta evidente al mismo tiempo que los procesos de valoración ética deberán ponderar también muchos otros datos, principios y directrices de carácter social, cultural, científico o técnico.

2 He analizado ya anteriormente esta problemática en dos ocasiones: primero en el estudio "Biotecnología: la nueva frontera de los derechos humanos" (Horizontes de la Filosofia del Derecho. Homenaje a Luis García San Miguel, Tomo I, Universidad de Alcalá, 2002, pp. 547-574), después, en forma más sintética, en "Biotecnología y derechos humanos: presente y futuro", lección impartida en A Coruña el 19 de julio de 2002, en un curso de verano sobre Investigaciones Médicas, Derecho y Dignidad Humana. Ahora no he hecho más que replantear las principales cuestiones ante los participantes en las Jornadas sobre bioética y derecho, que tuvieron lugar en Melilla durante los días 10-12 de diciembre de 2002.

3 El detalle de estos y otros datos, por ejemplo, en S. Prevris (Biotecnología. Una nueva revolución industrial, cit., pp. 4-5), S. GRISOLIA ("La Biotecnología en el tercer milenio", cit. pp. 7-8) o I. ZarazaGa BurLLLo ("Biotecnología genética en agricultura y ganadería (de la producción a la carta... a las nuevas normas ético-jurídicas", cit., pp. 332-336)]

\section{Según J. R. LaCadena ("Células troncales} humanas: ciencia y ética", en Moralia. Revista de ciencias morales, Vol. XXIV (2001-4), p. 433), "la utilización de la terapia celular, basada en la transferencia de células o tejidos a los tejidos u órganos dañados, es una de las grandes esperanzas de la Medicina del futuro"

5 De momento, las actuaciones sobre los seres humanos parecen haberse limitado a la selección del sexo de los hijos, pero el camino hacia la elección de cualquier otro rasgo del genotipo del individuo que va a nacer está ya abierto. Y, en consecuencia, los términos del debate ético se han puesto de manifiesto con suficiente claridad. Asi, E. Garzón Valuís ("QQué puede ofrecer la ética a la medicina?", en el libro colectivo Bioética y Derecho.

Fundamentos y problemas actuales, [R. Vázquez, comp.], Itam-FCE, México, 1999, pp. 54/55), F. MaNtovanI ("Investigación en el genoma humano y manipulaiones genéticas", en el libro colectivo Biotecnología y Derecho. Perspectivas en Derecho Comparado, cit., pp. 77-81), H. Nys ("Terapia génica humana", en el libro colectivo Biotecnologia y Derecho, cit., pp. 207/210) o D. TetTamavzi (Bioetica. Difendere le frontiere della vita, Piemme, Casale Monferrato, 1996, pp. 219/233) han delimitado ya, entre otros muchos y desde. perspertivas doctrinales bastante distantes, el campo de actuación de los diagnósticos y las terapias génicas, así como su respectivo horizonte de riesgos.

6 Hoy se tiene la creencia de que debemos fiarnos de los conocimientos de los científicos, pero muchos piensan que no en demasía, pues podría ocurrir que la inevitable limitación de esos conocimientos les colocara de nuevo en una situación similar a aquéllas otras del pasado en que no fueron capaces de prever el desarrollo de bacterias resistentes a los antibióticos o los dañinos efectos de ciertos medicamentos estrella [como la tristemente famosa talidomida] y de algunos de los insecticidas más universalmente empleados [como el DDT]. P. UNaI.KAT ("Alubias, genes y temas. La necesidad de precaución", en el libro colectivo Biotecnología y Derecho. Perspectivas 
en Derecho Comparado, cit., pp. 400-401) se ha apuntado irónicamente a esta desconfianza de partida.

7 Basta con contrastar, por ejemplo, las correspondientes indicaciones de R. JUNQQLERA DE Estéfan ("Los Derechos Humanos en la Era de la biotecnología", en el libro colectivo Utopía y realidad de los Derechos Humanos en el cincuenta aniversario de su Declaración Universal [N. MARTÍNEZ MonáN edit], UNED, Madrid, 1999, pp. 102-103), L. A. MArozzo ("La biotecnología y el derecho a la identidad", en Cuadernos de Bioética, VII, 25, 1996, p.), M. PalAcios ("Genes y técnicas (bioética)", en $E l$ libro de la sexualidad, El País, Madrid, 1992, p. 343) o La Declaración Universal sobre el Genoma Humano y los Derechos Humanos (artículos 5-8 y 12, sobre todo).

8 Por su parte, la Declaración Americana de los Derechos y Deberes del Hombre (en su artículo 4) y la Carta Social europea (en sus artículos 4 y 14) habían proclamado ya este mismo derecho de manera incidental, al consagrar el derecho a beneficiarse de servicios de bienestar social o el derecho de los trabajadores a una remuneración capaz de proporcionarles un nivel de vida decoroso.

9 Como he señalado ya en otra ocasión ("Dimensión científica de los derechos del hombre", en el libro colectivo Los Derechos Humanos. Significación, estatuto jurídico y sistema [J. L. Cascajo Castro y Otros], Universidad de Sevilla, Sevilla, 1979, pp. 122124), una interpretación integradora del derecho a la vida llevaría a fundir en él todos aquellos derechos que contribuyen de forma directa a la conservación de la propia vida y a su realización en constante plenitud.

10 Por eso se mira con esperanza al futuro, pensando que problemas actuales tan acuciantes como la persistencia de varias enfermedades endémicas, la escasez de alimentos, la desertización galopante, el agotamiento de los recursos energéticos, la esquilmación de los fondos marinos serán pronto resueltos mediante la generalización de determinadas actuaciones biotecnológicas.

11 No existe aún acuerdo definitivo sobre el número de enfermedades físicas graves que están determinadas por genes. Hace una treintena de años, eran conocidas unas dos mil; hoy se habla ya de una cantidad aproximada a las cuatro mil

12 En cualquier caso, puede entenderse que toda intervención biotecnológica sobre un organismo vivo constituye una flagrante intromisión en la integridad del sujeto, con independencia de que esa intromisión le produzca efectos beneficiosos o perjudiciales. Del mismo modo que la profundidad, el alcance y el propio significado de la intromisión dependerán del nivel en que actúe la respectiva intervención. Si ésta se realiza en el nivel somático, sus efectos serán poco profundos y quedarán circunscritos al propio individuo afectado. Pero si la intervención se hace en las células germinales o en los embriones, no sólo condicionará en su misma raíz el equipamiento vital del sujeto directamente afectado, sino también, con toda probabilidad, el de sus descendientes, por lo que podría afirmarse que tales intervenciones alteran de alguna forma el equipamiento vital de la especie.

13 El 04-10-02 nació Adam en uno de los Estados Unidos de Norteamérica. El niño había sido gestado a partir de un embrión elegido mediante diagnóstico genético preimplantatorio y manipulado para eliminar el gen que provoca la aparición de la 'anemia de Franconi', con el fin de hacer posible un trasplante que permitiera salvar la vida de una hermana que padecía dicha enfermedad.

14 Ver, por ejemplo, F. Mantovanl, "Investigación del genoma humano y manipulaciones genéticas", en el libro colectivo Biotecnología y 
Derecho. Perspectivas en Derecho Comparado, cit., pp. 216-217. El principio ha sido expresamente consagrado por el artículo 5 del Convenio sobre los Derechos Humanos y la Biomedicina.

15 En efecto, no puede pasarse por alto el significativo dato de que, en última instancia, la individual autonomía moral y política de cada ciudadano solamente encuentra realización en el seno de la organización social, quedando siempre, por tanto, automáticamente limitada por la presencia de los derechos de los demás ciudadanos y por los consiguientes deberes que cada uno tiene hacia éstos y hacia la comunidad. Y, desde este punto de vista, ha de reconocerse también que la comunidad ( $y$, en consecuencia, la propia organización estatal) tiene siempre algún grado de legitimación para imponer a los individuos cierto tipo de actuaciones, aunque éstas vayan en menoscabo de su autonomía personal o de su intimidad.

16 De hecho, se viene hablando de él desde hace varios años en diferentes foros y ámbitos. Así, en 1982, la Recomendación 934 sabre la ingeniería genética, de la Asamblea Parlamentaria del Consejo de Europa, mencionaba ya expresamente este derecho, aunque lo vinculaba, con notable imprecisión, al derecho a la vida y al derecho a la dignidad. Afirmaba, en efecto, esa Recomendación que "los derechos a la vida y a la dignidad humana protegidos por los artículos 2 y 3 del Convenio Europeo sobre Derechos Humanos implican el derecho a heredar un patrimonio genético que no haya sido manipulado". Además, la

Recomendación incluía asimismo, en su apartado 7, b, la sugerencia de que el Comité de Ministros previera "el reconocimiento expreso, en el Convenio Europeo de Derechos del Hombre, del derecho a un patrimonio genético que no haya sufrido ninguna manipulación, salvo en aplicación de ciertos principios reconocidos como plenamente compatibles con el respeto de los derechos humanos (por ejemplo, en el campo de las aplicaciones terapéuticas)". Y esa misma sugerencia fue recogida en el año 1986 por el principio 1 de la Recomendación 1046, del Consejo de Europa, relativa a la utilización de embriones y fetos humanos con fines diagnósticos, terapéuticos, científicos, industriales $y$ comerciales.

17 "Genética y Derecho", en el libro colectivo Biotecnologia y Derecho. Perspectivas en Derecho Comparado [C. M. ROMEO CASABONA, editor], Cátedra de Derecho y Genoma Humano, Editorial Comares, Bilbao-Granada, 1998, pp. 25-27. Por añadidura, la afirmación de este nuevo derecho obligaría a resolver una amplia batería de interrogantes previos cuya respuesta no parece fácil en la actualidad. Por ejemplo, el derecho al propio patrimonio genćtico àha de ser entendido como un derecho individual, como un derecho colectivo de grupo o como un derecho cuya titularidad corresponde a la humanidad en su conjunto?, ¿quién es el titular directo de ese derecho: los individuos y generaciones actuales de cada momento o más bien los futuros?, ¿cuáles son los elementos integrantes de ese patrimonio que se constituye en contenido del derecho y, por consiguiente, en barrera que no podrá ser franqueada en ningún caso por las actuaciones biotecnológicas eugenésicas: los de la actual estructura óntico-existencial del hombre o los que vienen estando presentes en los seres humanos desde las primeras etapas de su evolución?

18 Según ha establecido el artículo 15 del Convenio sobre los Derechos Humanos y la Biomedicina, "la investigación científica en el terreno de la biologia y la medicina se ejerce libremente, con sujeción a las disposiciones de este Convenio y a las otras disposiciones jurídicas que aseguran la protección del ser humano".

19 Por ejemplo, la autonomía, la integridad psicofísica o el patrimonio genético de los seres animados que resulten involucrados en 
los procesos de investigación. Pero ese conflicto debe ser siempre contrastado; no puede darse por supuesto. De ahí que, en relación con el derecho a la libertad de investigación y con las limitaciones que se pretende imponer a su ejercicio desde la defensa del llamado patrimonio genético humano, D. Gracia Gtilléx ("Libertad de investigación y biotecnología", en el libro colectivo Ética y Biotecnología [J. GAFo, editor], Fundación Humanismo y Democracia, Fundación Konrad Adenauer, Universidad de Comillas, Madrid, 1993, pp. 22 y ss.) no ha dudado en afirmar que se está incurriendo una vez más en la vieja falacia naturalista.

$20 \mathrm{~A}$ veces se afirma expresamente la subordinación de la libertad de investigación a todos los demás derechos humanos. Así lo hace, por ejemplo, La Declaración Universal sobre el Genoma Humano y los Derechos Humanos en su artículo 10, al establecer que "ninguna investigación relativa al genoma humano (...) podrá prevalecer sobre el respeto de los derechos humanos, de las libertades fundamentales $\mathrm{y}$ de la dignidad humana del individuo".

Por otra parte, resulta obvio que el ejercicio de la libertad de investigación, en cuanto derecho constitucionalmente reconocido (es decir, en cuanto derecho fundamental), puede estar sometido a cualesquiera limitaciones que establezca el propio sistema constitucional de reconocimiento y ejercicio, sean o no conformes con las exigencias derivadas del carácter humano de tal derecho fundamental. Ahora bien, no creo que esté justificada la distinción tripartita que se hace habitualmente dentro del análisis doctrinal de las posilles limitaciones de la libertad de investigación. (Ver, por ejemplo, la posición que mantiene $\mathrm{C}$. M. Romeo Casabona en su estudio "Consideraciones jurídicas sobre las técnicas genéticas", Anuario de Filosofia del Derecho, Nueva Época, XII, 1995, pp. 22-23).
21 Desde el punto de vista de la axiologia de los derechos humanos, la aplicación de los conocimientos genéticos a la eliminación de deficiencias positivas o negativas, sean somáticas o genéticas, no parece contraindicada, en tanto en cuanto no resulte manifiestamente lesionado algún derecho humano preferente. Pero parece también evidente (al menos, en principio) que cualquier individuo o grupo puede, en el ámbito de su respectiva autonomía, optar por mantener su propio equipamiento psicolísico en el nivel de desarrollo alcanzado hasta ese momento. $Y$, en esa medida, podría poner también límites a las diferentes prácticas tendentes a la eliminación de determinadas taras o al desarrollo de determinadas cualidades. El momento difícil surgiría una vez más cuando el interés o la voluntad de los individuos entrara en conflicto con el interés o la voluntad del grupo humano políticamente organizado: icuál debería prevalecer?

22 En consecuencia, como ha proclamado C. M. Romeo Casabona ("Genética y Derecho", cit., p. 31), "los poderes públicos -pero no sólo ellos- deben asumir la responsabilidad de promover la ciencia y la investigación científica y técnica en beneficio del interés general".

23 Así y a modo de ejemplo, en relación con las exigencias del respeto a la integridad psicofísica o a la intimidad, deberá resolverse en cada caso dónde está el mejor derecho: ¿en la intimidad e integridad del seropositivo o en la salud y vida de quienes tienen el riesgo de contagio (para el supuesto de que llegaran a establecer con él algún tipo de contacto arriesgado)?; ien la intimidad e integridad del presunto padre o madre o en el conocimiento de su propia identidad parental por parte del presunto hijo?; ien la intimidad e integridad del presunto agresor y delincuente o en el honor, la libertad y la vida del presunto inocente? 